\title{
Atypical Protein Kinase C Is a Novel Mediator of Dopamine- Enhanced Firing in Nucleus Accumbens Neurons
}

\author{
F. Woodward Hopf, William S. Mailliard, Gilda F. Gonzalez, Ivan Diamond, and Antonello Bonci \\ Ernest Gallo Clinic and Research Center, Department of Neurology, University of California, San Francisco, Emeryville, California 94608
}

\begin{abstract}
Current concepts suggest that nucleus accumbens (NAcb) dopamine mediates several motivated and addictive behaviors. Although the role of protein kinase A (PKA) and dopamine and cyclic adenosine $3^{\prime}, 5^{\prime}$ monophosphate-regulated phosphoprotein $32 \mathrm{kDa}$ in NAcb dopamine receptor throughput has been studied extensively, the contribution of protein kinase $\mathrm{C}$ (PKC) to NAcb firing is poorly understood. Here we show that dopamine-mediated enhancement of spike firing in NAcb shell medium spiny neurons was prevented by the PKC inhibitor bisindolylmaleimide but not by the phospholipase C inhibitor 1-[6-((17b-3-methoxyestra-1,3,5(10)-trien-17-yl) amino)hexyl]-1H-pyrrole-2,5-dione, suggesting a role for a diacylglycerol-independent atypical PKC (aPKC) isoform. In this regard, modulation of firing by dopamine was prevented by intracellular perfusion of a pseudosubstrate peptide inhibitor for aPKCs. We also provide evidence, using an in vitro kinase assay, that dopamine receptor activation increased aPKC activity in striatal membranes. Finally, direct activation of PKA with forskolin enhanced firing even during inhibition of aPKCs, suggesting that aPKCs acted upstream of PKA activation. Thus, aPKCs appear to mediate dopaminergic enhancement of spike firing in the NAcb shell, and may therefore play a critical role in NAcb- and dopamine-dependent goal-directed behaviors.
\end{abstract}

Key words: atypical; protein kinase C; accumbens; dopamine; action potential; firing

\section{Introduction}

Dopamine in the nucleus accumbens (NAcb) has long been considered an important modulator of addiction and goal-directed behaviors (Cardinal et al., 2002; Di Chiara, 2002), with a role for dopamine proposed in primary reward, learning, and memory, and as an indicator of the incentive salience of stimuli (SmithRoe and Kelley, 2000; Robinson and Berridge, 2001; Cardinal et al., 2002; Di Chiara, 2002; Schultz, 2002). NAcb dopamine can invigorate or enhance a number of behaviors, ranging from selfadministration of addictive drugs and dopaminergic agonists (Hodge et al., 1997; Ikemoto et al., 1997) to processing of cueinformed predictions (Schultz, 2002).

Dopamine interacts with two subfamilies of G-proteincoupled receptors, with $D_{1}$-like $\left(D_{1}\right)$ receptors coupled to stimulatory $\mathrm{G}_{\mathrm{s}}$-like proteins and $\mathrm{D}_{2}$-like $\left(\mathrm{D}_{2}\right)$ receptors coupled to inhibitory $\mathrm{G}_{\mathrm{i} / \mathrm{o}}$ proteins (Missale et al., 1998). Although these two subfamilies usually have opposing effects on cAMP-dependent signaling, we observed previously that dopamine enhances spike firing in NAcb shell medium spiny neurons (MSNs) in vitro via

Received July 29, 2004; revised Dec. 14, 2004; accepted Dec. 20, 2004.

This work was supported by funds provided by the State of California for medical research on alcohol and substance abuse through the University of California, San Francisco (F.W.H., A.B.), by the Alcoholic Beverage Medical Research Foundation, and by Department of the Army Grant DAMD17-0110803 (F.W.H., I.D.). The United States Army Medical Research Acquisition Activity (Fort Detrick, MD) is the awarding and administering acquisition office. The content of the information represented does not necessarily reflect the position or the policy of the United States Government, and no official endorsement should be inferred. We thank Drs. Dorit Ron and Robert Messing for comments regarding this manuscript and Drs. Lina Yao and Zhang Jiang for assistance with experiments.

Correspondence should be addressed to Antonello Bonci or Woody Hopf, Ernest Gallo Clinic and Research Center, Department of Neurology, University of California, San Francisco, 5858 Horton Street, Suite 200, Emeryville, CA 94608. E-mail: bonci@itsa.ucsf.edu or woody@egcr.net.

DOI:10.1523/JNEUROSCI.3099-04.2005

Copyright $\odot 2005$ Society for Neuroscience $\quad$ 0270-6474/05/250985-05\$15.00/0 postsynaptic coactivation of $\mathrm{D}_{1}$ and $\mathrm{D}_{2}$ receptors and signaling through $\mathrm{G}$-protein $\beta \gamma$ subunits $\left(\mathrm{G}_{\beta \gamma}\right)$ and protein kinase $\mathrm{A}$ (PKA) (Hopf et al., 2003). Importantly, several goal-directed behaviors require both $D_{1}$ and $D_{2}$ receptor signaling in the NAcb (Hiroi and White, 1991; Ikemoto et al., 1997; Hopf et al., 2003), including ethanol self-administration, which requires PKA signaling (Wand et al., 2001) and is significantly reduced by inhibition of $\mathrm{D}_{1}$ or $\mathrm{D}_{2}$ receptors (Hodge et al., 1997) or $\mathrm{G}_{\beta \gamma}$ (Yao et al., 2002) within the NAcb.

In addition to PKA (Wand et al., 2001; Beninger et al., 2003), protein kinase $\mathrm{C}(\mathrm{PKC})$ isoforms are implicated in a number of addictive behaviors (Cervo et al., 1997; Van der Zee and Douma, 1997; Pierce et al., 1998; Aujla and Beninger, 2003). However, the role of PKC in postsynaptic dopamine receptor signaling in the NAcb is poorly understood. NAcb PKC plays a role in both amphetamine conditioned place preference (CPP) (Aujla and Beninger, 2003) and sensitization to cocaine (Pierce et al., 1998). Both of these behaviors likely require NAcb dopamine (Hiroi and White, 1991; Di Chiara, 2002), and PKC modulates dopamine release in the striatum (Browman et al., 1998), leaving open the question of the locus of interaction of dopamine and PKC. Thus, we examined whether PKC is necessary for the dopaminergic enhancement of spike firing in NAcb shell MSNs.

\section{Materials and Methods}

Slice preparation and electrophysiology. Coronal slices $(300 \mu \mathrm{m})$ were prepared from male postnatal day 22 (P22) to P28 Sprague Dawley rats and maintained at $32^{\circ} \mathrm{C}$ in carbogen-bubbled artificial CSF (ACSF) (in mм: $126 \mathrm{NaCl}, 1.6 \mathrm{KCl}, 1.2 \mathrm{NaH}_{2} \mathrm{PO}_{4}, 1.2 \mathrm{MgCl}_{2}, 2.4 \mathrm{CaCl}_{2}, 18 \mathrm{NaHCO}_{3}$, and 11 glucose, $\mathrm{pH}$ 7.2-7.4, mOsm 301-305) for $30 \mathrm{~min}$ to $5 \mathrm{~h}$ before experiments. During experiments, slices were continuously perfused $(\sim 2$ 
$\mathrm{ml} / \mathrm{min}$ ) with $31-32^{\circ} \mathrm{C}$ ACSF supplemented with CNQX $(10 \mu \mathrm{M})$, picrotoxin $(50 \mu \mathrm{M})$, and sodium metabisulfite $(50 \mu \mathrm{M})$ (Hopf et al., 2003). For experiments with bisindolylmaleimide and 1-[6-((17b-3methoxyestra-1,3,5(10)-trien-17-yl) amino)hexyl]1H-pyrrole-2,5-dione (U73122), slices were preexposed for 30-60 $\mathrm{min}$ to enable adequate penetration, and whole-cell patch was achieved 10-15 min before dopamine application.

All patch-clamp experiments were performed using visualized infrared-differential interference contrast and whole-cell recording with 2.5-3.5 $\mathrm{M} \Omega$ electrodes filled with potassium methanesulfonate solution: $0.95 \% \mathrm{KOH}$ (v/v), $0.76 \%$ methanesulfonic acid (v/v), 0.18\% hydrochloric acid (v/v), $20 \mathrm{~mm}$ HEPES, $0.2 \mathrm{~mm}$ EGTA, $2.8 \mathrm{~mm} \mathrm{NaCl}, 2.5 \mathrm{mg} / \mathrm{ml} \mathrm{MgATP}$, and $0.25 \mathrm{mg} / \mathrm{ml}$ GTP, pH 7.2-7.4, 275-285 mOsm. Series resistance correction was $15-20 \mathrm{M} \Omega$. To elicit spike firing, a series of $300 \mathrm{~ms}$ current pulses was applied every $30 \mathrm{~s}$ using Clampex 8.0 and an Axo-1D or 700A patch amplifier (Axon Instruments, Foster City, CA) in current-clamp mode. A range of current pulses, with $20 \mathrm{pA}$ between each current step, was applied so that the initial current pulse for each neuron was just subthreshold for firing and the final current pulse elicited 8-10 spikes.

Analysis of spike firing. All such data were analyzed using Axograph (Axon Instruments) as described previously (Hopf et al., 2003). Spike firing rates during the $3 \mathrm{~min}$ before addition of the reagent were averaged, and this value was normalized to $100 \%$. The same current pulse was used for all time points of a given cell to determine changes in firing rate.

All data are shown as mean \pm SEM. Unless otherwise indicated, all statistics were performed using a two-tailed, unpaired $t$ test. Kinase activity experiments were analyzed with a paired $t$ test.

Preparation of homogenates. Coronal slices from six animals were distributed into two chambers to allow a paired comparison of kinase activity in slices with and without dopamine receptor activation. Slices were incubated for $10-15 \mathrm{~min}$ with $75 \mu \mathrm{M}$ dopamine, a combination of $\mathrm{D}_{1}$ and $\mathrm{D}_{2}$ agonists $[10 \mu \mathrm{M}$ each of ( \pm )-6-chloro-7,8-dihydroxy-1-phenyl2,3,4,5-tetrahydro-1M-3-benzazepine (SKF81297) and quinpirole], or vehicle (CNQX, picrotoxin, sodium metabisulfite) and then removed and placed in ice-cold ACSF $\left(0.6 \mathrm{~mm} \mathrm{CaCl}_{2}\right)$ containing phosphatase inhibitors I and II at 1:100 (Sigma, St. Louis, MO). The NAcb/striatum was immediately removed using a $3 \mathrm{~mm}$ tissue punch, flash frozen in liquid nitrogen, and stored at $-80^{\circ} \mathrm{C}$. Tissue was homogenized using a glass/Teflon homogenizer ( 15 strokes) in buffer $\mathrm{H}$ (in mM: 10 Tris, $\mathrm{pH}$ 7.4, 5 EDTA, 5 EGTA) containing $320 \mathrm{~mm}$ sucrose [all buffers also contained protease inhibitor mixture (Roche, Indianapolis, IN) and phosphatase inhibitors I and II]. The homogenate was centrifuged at $1000 \times$ $g\left(10 \mathrm{~min}, 4^{\circ} \mathrm{C}\right)$, and the resultant supernatant was centrifuged at $165,000 \times g$ to generate membrane (pellet) and cytosolic (supernatant) fractions. The membrane pellet was solubilized by resuspending in buffer $\mathrm{H}$ containing $1 \%$ Triton X-100 and rotating at $4^{\circ} \mathrm{C}$ for $30 \mathrm{~min}$. The solubilized membranes were centrifuged at $18,000 \times \mathrm{g}\left(5 \mathrm{~min}, 4^{\circ} \mathrm{C}\right)$ to remove insoluble material, and the resulting supernatant was saved. Triton X-100 was also included in the cytoplasmic fraction.

Atypical PKC kinase activity assay. Kinase activity was performed as described previously (Huang et al., 2001). Ten micrograms of membrane or cytosolic protein were added to $5 \times$ assay dilution buffer (Upstate Biotechnology, Lake Placid, NY) and brought to $30 \mu \mathrm{l}$ with double distilled water containing 12-(2-cyanoethyl)-6,7,12,13-tetrahydro-13methyl-5-oxo-5H-indolo(2,3-a) pyrrolo(3,4-c)-carbazole (Gö-6976) [50 nM final concentration, to inhibit conventional PKC (cPKC) activity]. The reaction was initiated by adding $10 \mu \mathrm{l}$ of a $\mathrm{Mg}^{2+} / \mathrm{ATP}$ solution (Upstate Biotechnology) plus $0.5 \mu \mathrm{Ci}$ of $\left[\gamma^{-}{ }^{32} \mathrm{P}\right] \mathrm{ATP}(3000 \mathrm{Ci} / \mathrm{mmol})$ and $200 \mu \mathrm{M} \epsilon$-peptide. After incubation for $15 \mathrm{~min}$ at $30^{\circ} \mathrm{C}, 10 \mu \mathrm{l}$ was spotted onto Whatman (Maidstone, UK) p81 paper. Nonspecific radioactivity was removed by extensive washing in $1 \%$ phosphoric acid, and incorporated ${ }^{32} \mathrm{P}$ was determined by scintillation counting. For experi- ments concerning the effect of dopamine on atypical PKC (aPKC) activity in total homogenates, aPKC activity was defined as the proportion of total kinase activity in the homogenate inhibited by a myristylated atypical pseudosubstrate peptide inhibitor of aPKCs (aPKC-PS) (100 $\mu \mathrm{M}$; Biosource International, Camarillo, CA), relative to scrambled control peptide $(100 \mu \mathrm{M})$. aPKC activity in dopamine-exposed slices was expressed relative to the aPKC activity in paired vehicle-exposed slices.

Immunoprecipitation and aPKC kinase activity assay. For experiments using receptor-specific agonists to activate dopamine receptors, $75 \mu \mathrm{g}$ of protein was immunoprecipitated in $250 \mu \mathrm{l}$ with $4 \mu \mathrm{g}$ of anti-PKC $\zeta$ monoclonal antibody (Santa Cruz Biotechnology, Santa Cruz, CA) for $1 \mathrm{~h}$ at $4^{\circ} \mathrm{C}$. Immunoprecipitated protein was recovered with $20 \mu \mathrm{l}$ of protein-G agarose, and the pellet was washed twice with buffer $\mathrm{H}$ plus $1 \%$ Triton X-100 and once with $1 \times$ assay dilution buffer (Upstate Biotechnology). The pellet was resuspended in $20 \mu$ l of $1 \times$ assay dilution buffer plus $200 \mu \mathrm{M} \epsilon$-peptide and $10 \mu \mathrm{l}$ of $\mathrm{Mg}^{2+} / \mathrm{ATP}$ mixture (Upstate Biotechnology) plus $0.5 \mu \mathrm{Ci}$ of $\left[\gamma^{-32} \mathrm{P}\right] \mathrm{ATP}(3000 \mathrm{Ci} / \mathrm{mmol})$. Activity of aPKC was determined as described above.

Reagents. Unless otherwise indicated, all reagents were made at 1:1000 stock and purchased from Sigma or RBI (Poole, UK). U73122, bisindolylmaleimide, and Gö-6976 were from Calbiochem (La Jolla, CA). PKA inhibitor fragment (6-22) amide (PKI) was from Tocris Cookson (Ballwin, MO). Most reagents were prepared fresh each day. Dopamine and PKI were dissolved in ACSF and distilled water, respectively. Dopamine receptor agonists, U73122, bisindolylmaleimide-I, forskolin, and Gö-6976 were dissolved in DMSO. A 2 mm stock of aPKC-PS (Ling et al., 2002) or the myristylated scrambled control (RLYRKRIWRSAGR; synthesized by Biosource International) was dissolved in distilled water and then diluted 1:1000 into the internal solution described above.

\section{Results}

Dopaminergic enhancement of spike firing requires $\mathrm{PKC}$ but not phospholipase $\mathrm{C}$

Whole-cell recordings in current-clamp mode were obtained from MSNs from the NAcb shell (Hopf et al., 2003). The resting membrane potential of each neuron was maintained at approximately $-80 \mathrm{mV}$ throughout the experiment by injection of DC through the patch amplifier. As reported previously (Hopf et al., 2003), dopamine (75 $\mu \mathrm{M})$ enhanced spike firing in the NAcb shell MSNs in the presence of the $0.1 \%$ DMSO vehicle $(n=8 ; p<$ 0.05 ) (Fig. $1 A, B)$. Dopaminergic enhancement of firing was significantly reduced by the PKC inhibitor bisindolylmaleimide (1 $\mu \mathrm{M} ; n=6$ ) (Fig. $1 A$ ), suggesting a role for PKC in the enhancement of spike firing by dopamine. $\mathrm{PKC}$ isoforms fall into three families: cPKC and novel PKC (nPKC) isoforms, which are activated by diacylglycerol produced by phospholipase C (PLC) and 
A
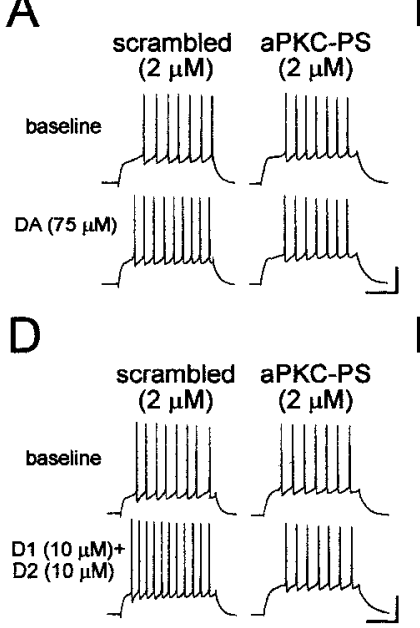

B

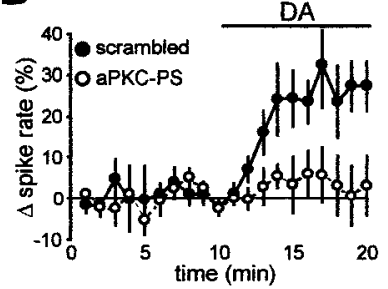

$E$

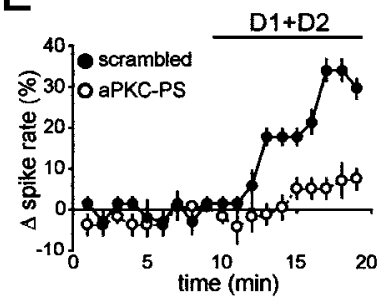

C

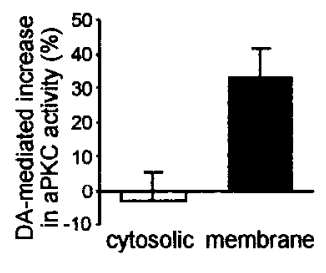

$F$

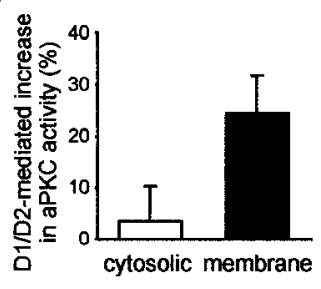

Figure 2. aPKC-PS prevented dopaminergic enhancement of spike firing. $A, B$, Intracellular perfusion of $2 \mu$ m aPKC-PS peptide, but not a scrambled control peptide, inhibited enhancement of spike firing by dopamine (DA). C, A 10 min exposure to dopamine increased aPKC activity in membranes from NAcb/striatal tissue but not in the cytoplasm. D, E, Enhancement of spike firing by coexposure to the $D_{1}$ agonist SKF81297 and the $D_{2}$ agonist quinpirole was inhibited by intracellular perfusion of aPKC-PS but not by the scrambled control peptide. F, A 10 min exposure to SKF81297 and quinpirole in combination enhanced aPKC activity in PKC $\zeta$ immunoprecipitates from NAcb/striatal membranes, with no significant change in the cytosol.

other enzymes, and aPKC isoforms, which do not require diacylglycerol or PLC (Parker and Murray-Rust, 2004). Because $\mathrm{G}_{\beta \gamma}$ can activate PLC (Rhee, 2001) and because dopaminergic enhancement of spike firing in the NAcb shell requires $\mathrm{G}_{\beta \gamma}$ (Hopf et al., 2003), we determined whether dopaminergic enhancement of spike firing occurred through activation of PLC. The PLC inhibitor U73122 $(1 \mu \mathrm{M})$ did not prevent the dopaminergic enhancement of firing $(n=6 ; p>0.05)$ (Fig. $1 B)$. Thus, dopaminergic enhancement of firing required PKC but was independent of PLC activity, suggesting a requirement for an aPKC isoform.

\section{Phorbol esters do not enhance spike firing}

To further exclude the role of CPKCs and nPKCs in dopaminergic enhancement of spike firing, we bath applied the phorbol ester phorbol-12,13-dibutyrate (PDBu; $0.5 \mu \mathrm{M}$ ), a potent activator of cPKCs and nPKCs but not aPKC isozymes. PDBu did not alter spike firing $(-1.3 \pm 5.2 \%$ change in firing; $n=10)$, suggesting that activation of $\mathrm{cPKC}$ and $\mathrm{nPKCs}$ did not modulate NAcb shell spike firing. Because we have shown previously that intracellular perfusion with $G_{\beta \gamma}$ enabled $D_{1}$ receptor agonists to enhance spike firing but had no effect alone (Hopf et al., 2003), we determined whether $\mathrm{CPKC}$ or $\mathrm{nPKC}$ activation might similarly enhance firing. However, PDBu did not enable a $\mathrm{D}_{1}$ agonist (SKF81297, 10 $\mu \mathrm{M} ; n=5$ ) or a $\mathrm{D}_{2}$ agonist (quinpirole, $10 \mu \mathrm{M} ; n=5$ ) to enhance firing (Fig. 1C), supporting the hypothesis that cPKCs and nPKCs are not required for dopaminergic enhancement of spike firing.

\section{A pseudosubstrate peptide inhibitor of aPKC prevents dopaminergic enhancement of spike firing}

To directly test the role of aPKCs in dopaminergic enhancement of firing, we perfused MSNs intracellularly with aPKC-PS ( $2 \mu \mathrm{M})$ (Ling et al., 2002) or an inactive scrambled peptide (RLYRKRIWRSAGR, $2 \mu \mathrm{M}$ ). Enhancement of spike firing by dopamine was significantly inhibited by aPKC-PS $(n=5)$ (Fig. $2 A, B)$ but not by the scrambled peptide $(n=5)$ (Fig. 2A,B). Similarly, enhancement of spike firing after coapplication of the $D_{1}$ agonist SKF81297 $(10 \mu \mathrm{M})$ and the $\mathrm{D}_{2}$ agonist quinpirole $(10 \mu \mathrm{M})$ was inhibited by aPKC-PS $(n=4)$ (Fig. $2 D, E)$ but not by the scrambled peptide $(n=6)$ (Fig. $2 D, E$ ). In addition, aPKC-PS had no effect alone on basal spike firing $(-0.2 \pm$ $4.4 \%$ change in firing; $n=20$ ), in agreement with our previous results showing no basal contribution of $\mathrm{D}_{1}$ or $\mathrm{D}_{2}$ receptors or PKA to spike firing (Hopf et al., 2003). These results strongly suggest that an $\mathrm{aPKC}$ was required for the dopaminergic enhancement of spike firing in NAcb shell MSNs.

Dopamine receptor activation increases aPKC activity in membranes

In other systems, aPKC-dependent changes in electrical excitability are accompanied by changes in localization and/or activity of aPKCs (Hrabetova and Sacktor, 1996; Gong et al., 1999; Liu et al., 2000; Cogolludo et al., 2003). We exposed slices to dopamine $(75 \mu \mathrm{M})$ and determined whether aPKC activity was altered in the NAcb/striatal region relative to vehicle-exposed slices. Slices were homogenized and separated into cytosolic and membrane fractions. Activity of aPKC in each fraction was then measured by phosphorylation of a substrate peptide. Kinase activity inhibited by aPKC-PS was considered to be a measure of aPKC activity (for details, see Materials and Methods). As shown in Figure 2C, dopamine significantly enhanced aPKC activity in the membrane fraction $(n=8 ; p<0.01)$ but did not affect activity in the cytoplasm $(p>0.05)$.

Because coactivation of $\mathrm{D}_{1}$ and $\mathrm{D}_{2}$ receptors enhanced spike firing in an aPKC-dependent manner, similar to dopamine, we asked whether $D_{1} / D_{2}$ coactivation would also increase aPKC activity. In these experiments, immunoprecipitation with an aPKCspecific antibody was used to determine aPKC activity in isolation from other kinases. $D_{1} / D_{2}$ coactivation significantly enhanced aPKC activity relative to vehicle-treated slices in the membrane fraction $(n=8 ; p<0.01)$ (Fig. $2 F)$, with no significant change in activity in the cytosol $(p>0.05)$ (Fig. $2 F)$. The immunoprecipitation was specific for aPKCs, because $>90 \%$ of the kinase activity was inhibited by aPKC-PS and $<10 \%$ of the activity was sensitive to the cPKC inhibitor Gö-6976 (data not shown). These results support the hypothesis that dopamine activates aPKCs and that aPKC activation is necessary for dopaminergic enhancement of spike firing in NAcb MSNs.

\section{Direct activation of PKA with forskolin enhances firing} without a requirement for aPKC

Because dopaminergic enhancement of firing requires PKA (Hopf et al., 2003) and PKA can activate aPKC (Huang et al., 2001), we examined whether enhancement of spike firing after direct activation of PKA with forskolin would be inhibited by aPKC-PS. Forskolin altered spike firing in a dose-dependent manner, with no enhancement of firing at $1 \mu \mathrm{M}(4.1 \pm 4.2 \%$ change in firing; $n=4)$ and significant enhancement of firing at 3 and $5 \mu \mathrm{M}(p<0.05)$ (Fig. 3A-C). However, forskolin-mediated enhancement of firing was not inhibited by aPKC-PS ( $3 \mu \mathrm{M}$ forskolin, $n=4 ; 5 \mu \mathrm{M}$ forskolin, $n=7$ ) (Fig. $3 A-C$ ) or the scrambled peptide ( $3 \mu \mathrm{M}$ forskolin, $n=4 ; 5 \mu \mathrm{M}$ forskolin, $n=4$ ) (Fig. $3 A-C)$, although it was prevented by intracellular perfusion with 
the PKA antagonist PKI $(20 \mu \mathrm{M} ;-1.3 \pm$ $5.3 \%$ change in spiking; $n=4$ ) (Fig. $3 A$ ), confirming that forskolin enhanced firing through PKA. Thus, direct PKA activation enhanced spike firing even when aPKCs were inhibited, suggesting that the contribution of aPKC to dopaminergic enhancement of firing occurred upstream of PKA activation and that $\mathrm{D}_{1}, \mathrm{D}_{2}$, and $\mathrm{aPKC}$ at the same cell were required for PKA activation. $\mathrm{D}_{1}$ and $\mathrm{D}_{2}$ could instead have acted on different neurons, for example, with $\mathrm{D}_{1}$-like receptors stimulating cholinergic interneurons (Centonze et al., 2003) and released acetylcholine synergizing with $\mathrm{D}_{2}$ on MSNs. However, the combined $\mathrm{D}_{1} / \mathrm{D}_{2}$ agonists enhanced firing in the presence of atropine $(1 \mu \mathrm{M})$, a cholinergic receptor antagonist $(24.9 \pm 5.1 \%$ change in firing; $n=5)$, in agreement with our previous results showing that dopaminergic enhancement of firing is not prevented by inhibition of synaptic release (Hopf et al., 2003).

\section{Discussion}

The present study shows that dopaminergic enhancement of spike firing in the NAcb shell required an atypical isoform of PKC. Enhancement of firing by dopamine was prevented by a general PKC inhibitor and by a specific peptide inhibitor of aPKCs but not by a PLC inhibitor. Also, spike firing was not altered by a phorbol ester, which activates cPKCs and nPKCs but not aPKCs. Furthermore, exposure to dopaminergic agonists increased the activity of membrane-associated aPKC. Finally, enhancement of spike firing after direct activation of PKA with forskolin did not require aPKC. Together, these results strongly suggest that an atypical isoform of PKC was required for dopaminergic enhancement of spike firing in NAcb shell MSNs and that aPKC contributed to enhancement of firing through action upstream of PKA activation.

In vitro, dopamine enhances spike firing in NAcb shell MSNs via cooperative activation of $D_{1}$ and $D_{2}$ receptors, as well as $G_{\beta \gamma}$ (Hopf et al., 2003), and the latter could mediate the activation of aPKCs (Parker and Murray-Rust, 2004). A number of behavioral studies related to motivation and addiction suggest a requirement for both $\mathrm{D}_{1}$ and $\mathrm{D}_{2}$ receptors in the NAcb (Hiroi and White, 1991; Hodge et al., 1997; Ikemoto et al., 1997). For example, animals will self-administer $\mathrm{D}_{1}$ and $\mathrm{D}_{2}$ agonists directly into the NAcb in combination but not alone (Ikemoto et al., 1997). Although there are relatively few studies of the role of NAcb PKC in addiction and motivation, expression of cocaine locomotor sensitization and amphetamine CPP both require NAcb PKC (Pierce et al., 1998; Aujla and Beninger, 2003), and amphetamine CPP requires both $\mathrm{D}_{1}$ and $\mathrm{D}_{2}$ receptors in the NAcb (Hiroi and White, 1991). Because dopamine-induced enhancement of firing requires aPKCs, aPKCs may play a critical role in goal-directed behaviors by regulating dopamine signaling. PKC is also implicated in a number of other addictive behaviors, although the brain region involved was not determined (Cervo et al., 1997).

Addictions may become entrenched by coopting normal memory-forming mechanisms (Smith-Roe and Kelley, 2000; Cardinal et al., 2002). Therefore, PKC might contribute to addictive behaviors by modulating learning and memory processes related to reward (Cervo et al., 1997). Many cellular and behavioral studies support a role for PKC in synaptic plasticity and memory formation (Hrabetova and Sacktor, 1996; Van der Zee
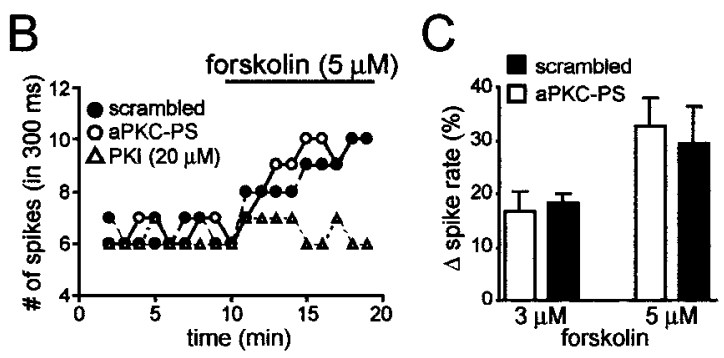

Figure 3. Enhancement of spike firing after direct activation of PKA by forskolin was not prevented by inhibition of aPKC. $A, B$, Examples showing enhancement of firing by forskolin that was inhibited by the PKA antagonist PKI but not by aPKC-PS or the scrambled peptide. C, Grouped data showing significant enhancement of spike firing by 3 or $5 \mu \mathrm{m}$ forskolin after intracellular srambled peptide.

and Douma, 1997; Sweatt et al., 1998; Ling et al., 2002), with a particular role for aPKCs in memory maintenance (Ling et al., 2002). Because NAcb dopamine appears to mediate several forms of learning (Smith-Roe and Kelley, 2000; Cardinal et al., 2002), dopamine-mediated activation of aPKC in the NAcb might contribute to learning during addictive or motivated behaviors.

Dopaminergic activation of firing requires PKA in addition to a cooperative interaction of $D_{1}$ and $D_{2}$ receptors (Hopf et al., 2003). Here, we show that aPKC is also required for dopaminergic enhancement of firing and that aPKC is likely to act upstream of PKA activation. However, the relationship between activation of $\mathrm{D}_{1}$ and $\mathrm{D}_{2}$ receptors and aPKC remains undetermined. Activation of aPKC could require concurrent $D_{1}$ and $D_{2}$ receptor stimulation or could require either the $D_{1}$ or the $D_{2}$ receptor alone, with a likely candidate perhaps being $D_{2}$ via release of $G_{\beta \gamma}$ and activation of the phosphatidylinositol-3-kinase pathway (Rhee, 2001; Parker and Murray-Rust, 2004). Future studies will be required to determine the dopamine receptor subtype(s) required for aPKC activation and the mechanism by which aPKC could contribute to PKA activation. Regardless of the underlying mechanism, it is interesting to note that synergy between $\mathrm{G}_{\mathrm{i}^{-}}$and $\mathrm{G}_{\mathrm{s}}$-linked receptors has been observed for several receptor types activated by drugs of abuse (Yao et al., 2003). Thus, cooperative interactions involving PKA and aPKC might occur during postsynaptic neurotransmitter signaling for receptors other than dopamine.

We should also note that dopaminergic enhancement of NAcb spike firing involves inhibition of the Kv1-type potassium channel (Hopf et al., 2003), similar to other studies suggesting that related $\mathrm{Kv}$-type channels are regulated by aPKCs (Gong et al., 1999; Cogolludo et al., 2003). Consistent with aPKC regulation of a membrane channel, we observed that dopamine increased aPKC activity in striatal membranes, perhaps because of increased localization of aPKC to the membrane (Cogolludo et al., 2003) or activation of aPKC present in the membrane (Liu et al., 2000). However, because aPKC is likely to act upstream of $\mathrm{PKA}$, it is unlikely that aPKC acts via direct interaction with $\mathrm{Kv} 1$ subunits via an intermediary protein, as has been reported previously (Gong et al., 1999).

NAcb dopamine is implicated in both memory formation (Smith-Roe and Kelley, 2000; Cardinal et al., 2002) and behavioral expression during NAcb-dependent behaviors (Hiroi and White, 1991; Hodge et al., 1997; Ikemoto et al., 1997; Cardinal et al., 2002; Di Chiara, 2002) (but see Cornish and Kalivas, 2000). Here, we demonstrate that dopamine receptor activation increases activity of aPKCs and that activation of aPKC is necessary for dopaminergic enhancement of spike firing in NAcb shell MSNs. Thus, dopaminergic activation of aPKCs in the NAcb may 
regulate memory formation as well as behavioral expression in relation to addictive or motivated behaviors.

\section{References}

Aujla H, Beninger RJ (2003) Intra-accumbens protein kinase C inhibitor NPC 15437 blocks amphetamine-produced conditioned place preference in rats. Behav Brain Res 147:41-48.

Beninger RJ, Nakonechny PL, Savina I (2003) cAMP-dependent protein kinase and reward-related learning: intra-accumbens Rp-cAMPS blocks amphetamine-produced place conditioning in rats. Psychopharmacology (Berl) 170:23-32.

Browman KE, Kantor L, Richardson S, Badiani A, Robinson TE, Gnegy ME (1998) Injection of the protein kinase C inhibitor Ro31-8220 into the nucleus accumbens attenuates the acute response to amphetamine: tissue and behavioral studies. Brain Res 814:112-119.

Cardinal RN, Parkinson JA, Hall J, Everitt BJ (2002) Emotion and motivation: the role of the amygdala, ventral striatum, and prefrontal cortex. Neurosci Biobehav Rev 26:321-352.

Centonze D, Grande C, Usiello A, Gubellini P, Erbs E, Martin AB, Pisani A, Tognazzi N, Bernardi G, Moratalla R, Borrelli E, Calabresi P (2003) Receptor subtypes involved in the presynaptic and postsynaptic actions of dopamine on striatal interneurons. J Neurosci 23:6245-6254.

Cervo L, Mukherjee S, Bertaglia A, Samanin R (1997) Protein kinases A and $\mathrm{C}$ are involved in the mechanisms underlying consolidation of cocaine place conditioning. Brain Res 775:30-36.

Cogolludo A, Moreno L, Bosca L, Tamargo J, Perez-Vizcaino F (2003) Thromboxane A2-induced inhibition of voltage-gated $\mathrm{K}^{+}$channels and pulmonary vasoconstriction: role of protein kinase $\mathrm{C} \zeta$. Circ Res 93:656-663.

Cornish JL, Kalivas PW (2000) Glutamate transmission in the nucleus accumbens mediates relapse in cocaine addiction. J Neurosci 20:RC89(1-5).

Di Chiara G (2002) Nucleus accumbens shell and core dopamine: differential role in behavior and addiction. Behav Brain Res 137:75-114.

Gong J, Xu J, Bezanilla M, van Huizen R, Derin R, Li M (1999) Differential stimulation of PKC phosphorylation of potassium channels by ZIP1 and ZIP2. Science 285:1565-1569.

Hiroi N, White NM (1991) The amphetamine conditioned place preference: differential involvement of dopamine receptor subtypes and two dopaminergic terminal areas. Brain Res 552:141-152.

Hodge CW, Samson HH, Chappelle AM (1997) Alcohol self-administration: further examination of the role of dopamine receptors in the nucleus accumbens. Alcohol Clin Exp Res 21:1083-1091.

Hopf FW, Cascini MG, Gordon AS, Diamond I, Bonci A (2003) Cooperative activation of dopamine $\mathrm{D}_{1}$ and $\mathrm{D}_{2}$ receptors increases spike firing of nucleus accumbens neurons via G-protein $\beta \gamma$ subunits. J Neurosci 23:5079-5087.

Hrabetova S, Sacktor TC (1996) Bidirectional regulation of protein kinase
$\mathrm{M} \zeta$ in the maintenance of long-term potentiation and long-term depression. J Neurosci 16:5324-5333.

Huang NK, Lin YW, Huang CL, Messing RO, Chern Y (2001) Activation of protein kinase $\mathrm{A}$ and atypical protein kinase $\mathrm{C}$ by $\mathrm{A}(2 \mathrm{~A})$ adenosine receptors antagonizes apoptosis due to serum deprivation in PC12 cells. J Biol Chem 276:13838-13846.

Ikemoto S, Glazier BS, Murphy JM, McBride WJ (1997) Role of dopamine $\mathrm{D}_{1}$ and $\mathrm{D}_{2}$ receptors in the nucleus accumbens in mediating reward. J Neurosci 17:8580-8587.

Ling DS, Benardo LS, Serrano PA, Blace N, Kelly MT, Crary JF, Sacktor TC (2002) Protein kinase $M \zeta$ is necessary and sufficient for LTP maintenance. Nat Neurosci 5:295-296.

Liu K, Hsiung S, Adlersberg M, Sacktor T, Gershon MD, Tamir H (2000) $\mathrm{Ca}^{2+}$-evoked serotonin secretion by parafollicular cells: roles in signal transduction of phosphatidylinositol $3^{\prime}$-kinase, and the $\gamma$ and $\zeta$ isoforms of protein kinase C. J Neurosci 20:1365-1373.

Missale C, Nash SR, Robinson SW, Jaber M, Caron MG (1998) Dopamine receptors: from structure to function. Physiol Rev 78:189-225.

Parker PJ, Murray-Rust J (2004) PKC at a glance. J Cell Sci 117:131-132.

Pierce RC, Quick EA, Reeder DC, Morgan ZR, Kalivas PW (1998) Calciummediated second messengers modulate the expression of behavioral sensitization to cocaine. J Pharmacol Exp Ther 286:1171-1176.

Rhee SG (2001) Regulation of phosphoinositide-specific phospholipase C. Annu Rev Biochem 70:281-312.

Robinson TE, Berridge KC (2001) Incentive-sensitization and addiction. Addiction 96:103-114.

Schultz W (2002) Getting formal with dopamine and reward. Neuron 36:241-263.

Smith-Roe SL, Kelley AE (2000) Coincident activation of NMDA and dopamine $D_{1}$ receptors within the nucleus accumbens core is required for appetitive instrumental learning. J Neurosci 20:7737-7742.

Sweatt JD, Atkins CM, Johnson J, English JD, Roberson ED, Chen SJ, Newton A, Klann E (1998) Protected-site phosphorylation of protein kinase C in hippocampal long-term potentiation. J Neurochem 71:1075-1085.

Van der Zee EA, Douma BR (1997) Historical review of research on protein kinase C in learning and memory. Prog Neuropsychopharmacol Biol Psychiatry 21:379-406.

Wand G, Levine M, Zweifel L, Schwindinger W, Abel T (2001) The cAMPprotein kinase A signal transduction pathway modulates ethanol consumption and sedative effects of ethanol. J Neurosci 21:5297-5303.

Yao L, Arolfo MP, Dohrman DP, Jiang Z, Fan P, Fuchs S, Janak PH, Gordon AS, Diamond I (2002) $\beta \gamma$ Dimers mediate synergy of dopamine D2 and adenosine A2 receptor-stimulated PKA signaling and regulate ethanol consumption. Cell 109:733-743.

Yao L, Fan P, Jiang Z, Mailliard WS, Gordon AS, Diamond I (2003) Addicting drugs utilize a synergistic molecular mechanism in common requiring adenosine and Gi- $\beta \gamma$ dimers. Proc Natl Acad Sci USA 100:14379-14384. 